\title{
Long non-coding RNA H19 promotes the migration and invasion of colon cancer cells via MAPK signaling pathway
}

\author{
WEIWEI YANG ${ }^{1}$, RAJKUMAR EZAKIEL REDPATH ${ }^{1}, \mathrm{CHONGYOU} \mathrm{ZHANG}^{2}$ and NING NING ${ }^{3}$ \\ ${ }^{1}$ Department of Pathology; ${ }^{2}$ Basic Medical College, Harbin Medical University, Harbin, Heilongjiang 150081; \\ ${ }^{3}$ Department of Gastrointestinal Surgery, International Hospital of Peking University, Beijing 102206, P.R. China
}

Received March 8, 2017; Accepted June 19, 2018

DOI: $10.3892 /$ ol.2018.9052

\begin{abstract}
Long non-coding RNA H19 has been identified to be dysregulated in a number of tumor types, and is closely associated with cancer progression. RAS/mitogen-activated protein kinase (MAPK) is an important intracellular signaling transduction pathway. Activation of the RAS-MAPK signaling pathway is one of the most frequent carcinogenic events in human cancer. However, the mechanism of H19 in promoting the migration and invasion of colorectal cancer (CRC) cells, and the association between H19 and RAS-MAPK signaling pathway is not well understood. The aim of the present study was to investigate the function of $\mathrm{H} 19$ on CRC metastasis and invasion, and assess the association between $\mathrm{H} 19$ and the RAS-MAPK signaling pathway. The migration and invasion of CRC cells were analyzed using Transwell migration and invasion assays. To elucidate the association between $H 19$ and the RAS-MAPK signaling pathway and determine the expression level of active RAS in CRC cells, Ras activity assay and Western blotting were performed. It was indicated that the overexpression of $\mathrm{H} 19$ was able to increase the migration and invasion of CRC cells and this may be mediated by the regulation of RAS activation. Therefore, H19 may promote metastasis and invasion in colorectal cancer by activating the RAS-MAPK signaling pathway.
\end{abstract}

\section{Introduction}

Colorectal cancer (CRC) is the third most common human malignancy and the fourth most common cause of

Correspondence to: Professor Chongyou Zhang, Basic Medical College, Harbin Medical University, 157 Baojian Road, Harbin, Heilongjiang 150081, P.R. China

E-mail: cyzhanghmu@sina.com

Professor Ning Ning, Department of Gastrointestinal Surgery, International Hospital of Peking University, 1 Science Road, Beijing 102206, P.R. China

E-mail: ningning301@126.com

Key words: colorectal cancer, H19, migration, invasion, RAS-mitogen-activated protein kinase cancer-associated mortality globally (1). In China, the morbidity of CRC has been increasing and was the fourth most common cause of cancer-associated mortality in 2011 (2). The lack of sensitivity to chemotherapy and metastasis are the most common reasons for treatment failure (3) and for the mortality of patients. Therefore, it is important to elucidate the underlying molecular mechanisms of migration and invasion of CRC cells.

Long non-coding RNAs (lncRNAs) are a type of non-coding RNA with $>200$ nucleotides in length and do not encode for proteins $(4,5)$. IncRNAs serve a function in tumorigenesis $(3,6-12)$ and have been identified in various types of cancer (3,7-11,13-21). IncRNA H19 is one type of lncRNA and is located on chromosome 11 in humans and serves an important function in mammalian development (22). According to previous studies, H19 is upregulated in numerous types of cancer, including CRC $(23,24)$, hepatocellular carcinoma $(25,26)$, esophageal $(27)$, bladder (28) and breast cancer $(29,30)$. The finding that H19 is overexpressed in cancer tissues suggests that it may serve an oncogenic function. However, the exact underlying molecular mechanism of $\mathrm{H} 19$ remains unclear.

The RAS/mitogen-activated protein kinase (MAPK) signaling pathway is an important pathway in human cancer. Tumorigenic mutations of RAS occur in $~ 30 \%$ of tumors. In this pathway, activated RAS triggers the activation of RAF and subsequently activated RAF phosphorylates and activates mitogen-activated protein kinase kinase (MEK), which phosphorylates and activates MAPK/extracellular signal-related kinase (ERK) (31). However, the association between H19 and the RAS-MAPK signaling pathway in colorectal cancer remains unresolved. In the present study, it was identified that $\mathrm{H} 19$ increases the migration and invasion of CRC cells by activating the RAS-MAPK signaling pathway.

\section{Materials and methods}

Cell culture and reagents. The human CRC cell lines SW480 and HCT116 were obtained from the Institute of Biochemistry and Cell Biology (Shanghai, China). The SW480 and HCT116 cells were cultured in RPMI-1640 medium (Gibco; Thermo Fisher Scientific, Inc., Waltham, MA, USA), $2 \%$ penicillin-streptomycin $(10 \mathrm{U} / \mathrm{ml})$ at $37^{\circ} \mathrm{C}$ in a $5 \% \mathrm{CO}_{2}$ atmosphere. MAPK inhibitor (PD098059) was 
purchased from Cell Signaling Technology, Inc. (Danvers, MA, USA). The SW480 and HCT116 cells were cultured with $45 \mu \mathrm{mol} / 1$ PD098059 when required.

Transfection. pWPXL lentiviral vectors were employed to overexpress H19 in SW480 and HCT116 cells (32). The full-length sequence of H19 (forward, 5'-GGATCCAGTTAG AAAAAGCCCGGGCT-3' and reverse, 5'-ACGCGTGCT GTAACAGTGTTTATTGA-3') was amplified and inserted into the pWPXL vector (cat. no. 12257; Addgene, Inc., Cambridge, MA, USA). A small interfering RNA (siRNA) against H19 (siRNA sequence, 5'-GCAGGACAUGACAUG GUCC-3') and a non-targeted sequence (negative control, NC, 5'-UCCGCUGACGACAAGGAUG-3') were synthesized by Shanghai GenePharma Co., Ltd. (Shanghai, China). The transfection of plasmid and siRNAs was conducted using Lipofectamine $2000^{\circledR}$ (Invitrogen; Thermo Fisher Scientific, Inc.) according to the manufacturer's protocol.

Reverse transcription-quantitative polymerase chain reaction $(R T-q P C R)$. Total RNA was extracted from cultured cells following transfection by TRIzol reagent (Takara Biotechnology Co., Ltd., Dalian, China), according to the manufacturer's protocol. A total of $2 \mu \mathrm{g}$ RNA was reverse transcribed into cDNA using a PrimeScript RT Master Mix Perfect Real Time kit (Takara Biotechnology Co., Ltd.). RT-qPCR was performed using an ABI 7900 RT-PCR system with a SYBR Premix Ex Taq kit (Takara Biotechnology Co., Ltd.). The $\mathrm{H} 19$ and reference gene $\alpha$-tubulin primers were synthesized by GenePharma (Shanghai GenePharma Co., Ltd., Shanghai, China). The RT-qPCR primers were as follows: H19 forward, 5'-CTGGGCAACGGAGGT GTA-3' and reverse, 5'-CTGGGAGGGTGTCTGCTTC-3'; $\alpha$-tubulin forward, 5'-ACCTTAACCGCCTTATTAGCCA-3' and reverse, 5'-ACATTCAGGGCTCCATCAAATC-3'. The thermocycling conditions were as follows: $95^{\circ} \mathrm{C}$ for $10 \mathrm{~min}$, followed by 39 cycles at $95^{\circ} \mathrm{C}$ for $10 \mathrm{sec}$ and $60^{\circ} \mathrm{C}$ for $40 \mathrm{sec}$. The analysis of RT-qPCR results was performed using the $2^{-\Delta \Delta \mathrm{Cq}}$ method (33).

Ras activity assay. Active Ras Pull-Down and Detection kit (Thermo Fisher Scientific, Inc.) was utilized according to the manufacturer's protocol. After $48 \mathrm{~h}$ of transfection, human CRC cells were harvested and prepared in accordance with the manufacturer's protocol. The cell samples were loaded onto a $10 \%$ SDS-PAGE gel followed by western blotting on nitrocellulose membrane according to the manufacturer's protocol, and the polyvinylidene difluoride membrane (PVDF) membranes were incubated with anti-Ras antibody.

Western blot analysis. Total protein was extracted from the human CRC cells using radioimmunoprecipitation assay buffer (Beyotime Institute of Biotechnology, Haimen, China). A total of $50 \mu \mathrm{g}$ protein was loaded into each lane on a $10 \%$ SDS-PAGE gel and transferred to PVDF membranes. The membranes were incubated in 5\% skimmed milk dissolved in TBST for $1 \mathrm{~h}$ at room temperature, followed by incubation with anti-Raf (1:1,200; cat. no. ab137435), anti-p-Raf (1:1,500; cat. no. ab173539), anti-ERK (1:2,000; cat. no. ab54230), anti-p-ERK (1:1,500; cat. no. ab50011), anti-MEK (1:1,000; cat. no. ab32091), anti-p-MEK (1:2,000; cat. no. ab96379) and anti-GAPDH (1:2,000; cat. no. ab9485; all from Abcam, Cambridge, MA, USA) overnight at $4^{\circ} \mathrm{C}$. The membranes were incubated with secondary peroxidase-conjugated antibody (1:1,500; cat. no. ab205718/ab205719; Abcam) for $1 \mathrm{~h}$ following washing with TBS. The membranes were assessed using an enhanced chemiluminescence kit (Beyotime Institute of Biotechnology). The relative level of each band was measured using ImageJ K.1.45 software (National Institutes of Health, Bethesda, MD, USA).

Transwell migration assay. A migration assay was conducted using Transwell chambers (pore size, $8 \mu \mathrm{m}$; Costar, Cambridge, MA, USA). Human colorectal cancer cells that overexpressed H19 or control human colorectal cancer cells $\left(2 \times 10^{4}\right)$ were trypsinized and re-suspended in $200 \mu 1$ serum-free RPMI-1640 medium. The cells were seeded into the upper Transwell chamber. The lower chambers were filled with $800 \mu \mathrm{l}$ complete RPMI-1640 medium with $10 \%$ fetal bovine serum (Gibco; Thermo Fisher Scientific, Inc.). Following incubation for $24 \mathrm{~h}$ at $37^{\circ} \mathrm{C}$, the cells on the upper side of the chamber were carefully scraped off with cotton swab. The cells that had migrated to the lower side of the chamber were fixed using $1 \%$ crystal violet for $15 \mathrm{~min}$ at room temperature before being counted. The images were captured using an inverted microscope (magnification, x200; Olympus Corporation, Tokyo, Japan). The number of cells that migrated were counted using ImageJ software.

Transwell invasion assay. Transwell invasion assay was performed using Transwell chambers with BD Matrigel coating the upper side of the Transwell insert (Costar). The cells were seeded, and the number of cells that invaded through the Matrigel insert were counted using the aforementioned method for the Transwell migration assay.

Statistical analysis. All statistical analyses were performed using SPSS software (version 17; SPSS, Inc., Chicago, IL, USA). The significance of the differences between two groups was assessed using Student's t-test. $\mathrm{P}<0.05$ was considered to indicate a statistically significant difference.

\section{Results}

Overexpression of $H 19$ promotes the migration and invasion of CRC cells. In order to elucidate the function of H19 in the migration and invasion of CRC cells, the pWPXL lentiviral vector was utilized to overexpress H19 in SW480 and HCT116 cells. In order to detect H19 expression in CRC cells, RT-qPCR was conducted. Compared with control CRC cells, overexpression of H19 in SW480 and HCT116 cells significantly elevated H19 expression levels (Fig. 1A; P<0.01). Whereas, knockdown of H19 in SW480 and HCT116 cells reduced H19 expression levels compared with CRC negative control cells (Fig. 1B; $\mathrm{P}<0.01)$. Transwell migration and invasion assays were performed to evaluate the migratory and invasive capacity of the CRC cells. The Transwell migration and invasion assays demonstrated that the overexpression of H19 in SW480 and HCT116 cells was able to promote the migration and invasion of CRC cells compared with the control treatment $(\mathrm{P}<0.01$; 

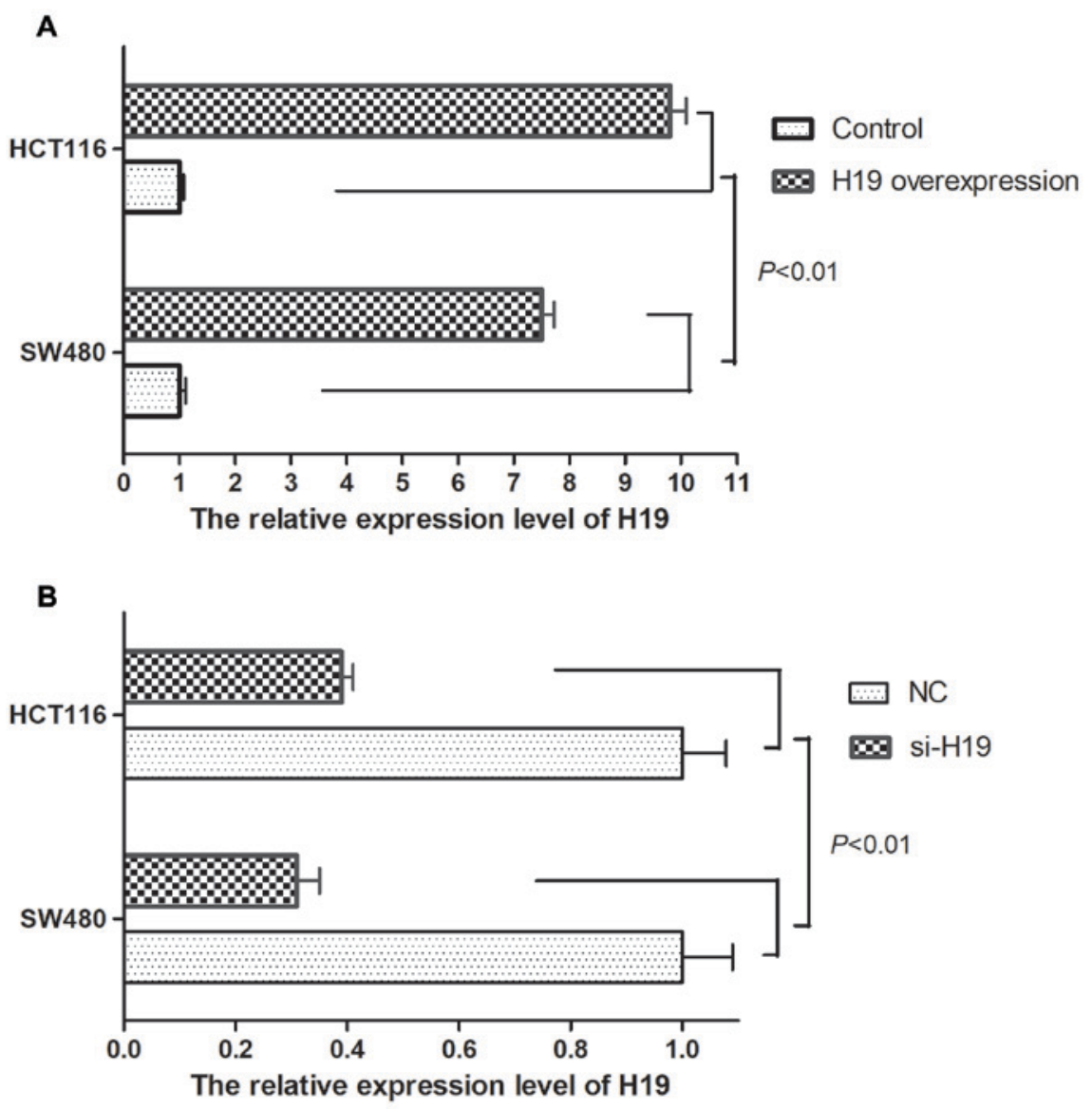

Figure 1. The relative expression levels of H19 in CRC cells. (A) Overexpression of H19 in SW480 and HCT116 cells significantly elevates H19 expression levels (B) Knockdown of H19 in SW480 and HCT116 cells reduces H19 expression levels.
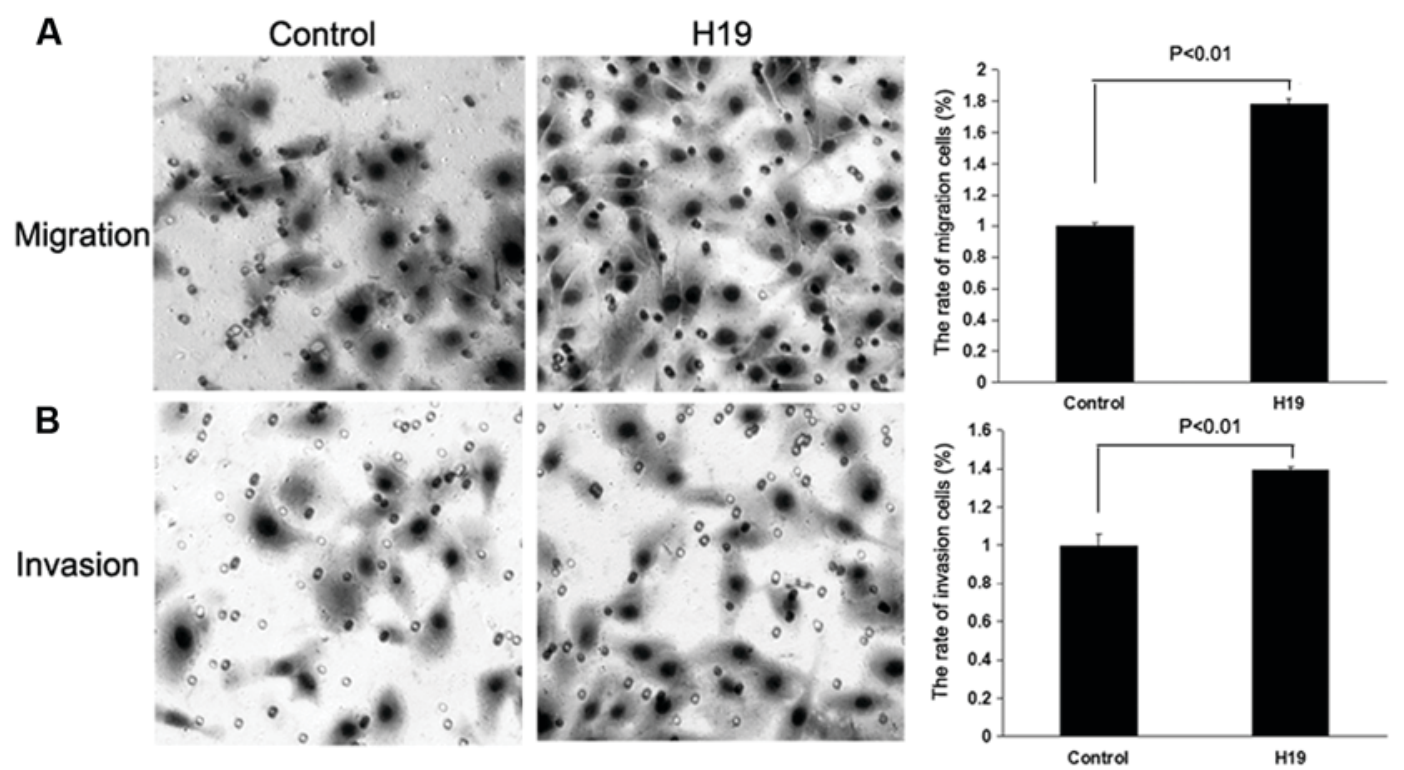

Figure 2. Overexpression of H19 increases the migration and invasion of HCT116 cells. (A) Overexpression of H19 increases the migration of HCT116 cells. (B) Overexpression of $H 19$ increases the invasion of HCT116 cells (magnification, x200).

Figs. 2 and 3), whereas the knockdown of H19 significantly decreased the migration and invasion of SW480 and HCT116 CRC cells compared with the control treatment group $(\mathrm{P}<0.01$ and $\mathrm{P}<0.05$; Figs. 4 and 5).
H19 regulates the activation of Ras. The underlying molecular mechanism of $H 19$ in promoting cell migration and invasion was investigated. A potential signaling pathway was identified which may be regulated by H19 
A
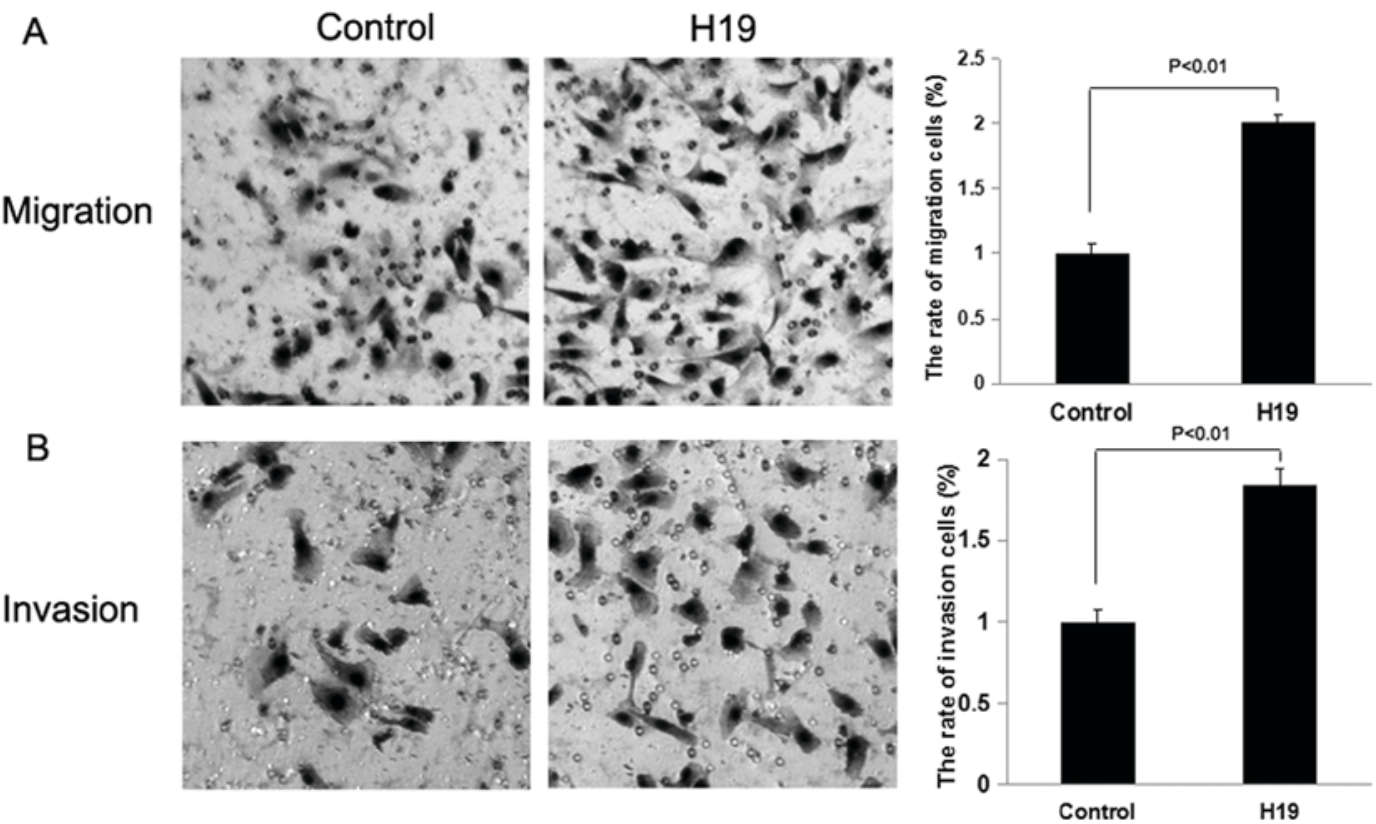

Figure 3. Overexpression of H19 increases the migration and invasion of SW480 cells. (A) Overexpression of H19 increases the migration of SW480 cells. (B) Overexpression of H19 increases the invasion of SW480 cells (magnification, x200).

A

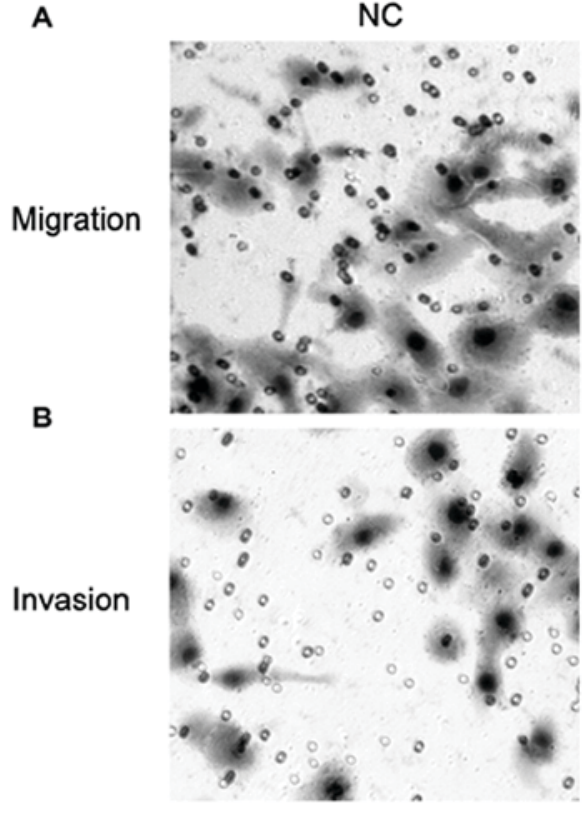

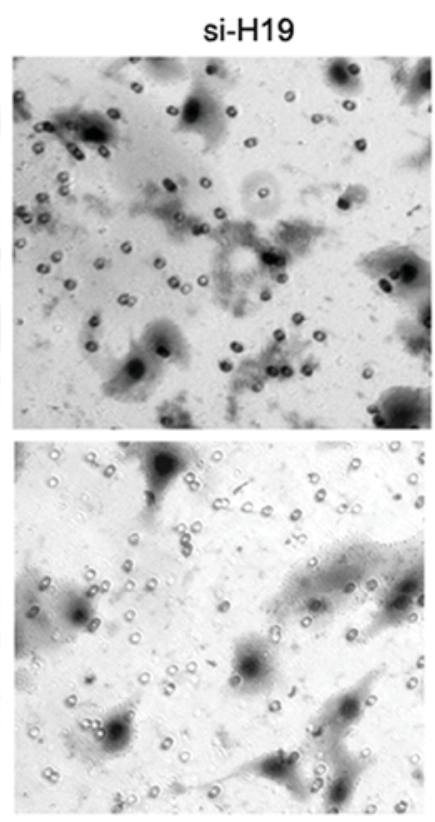

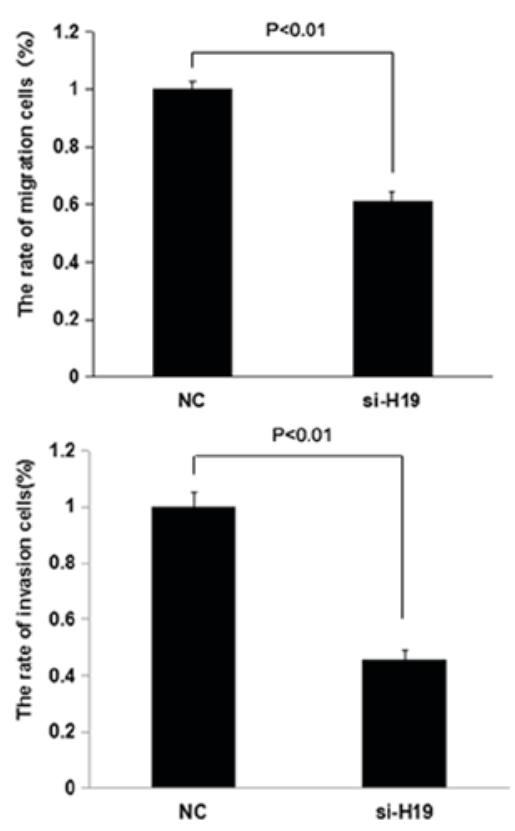

Figure 4. H19 knockdown inhibits the migration and invasion of HCT116 cells. (A) H19 knockdown inhibits the migration of HCT116 cells. (B) H19 knockdown inhibits the invasion of HCT116 cells (magnification, $\mathrm{x} 200$ ).

and is associated with migration and invasion of human CRC cells.

The RAS-MAPK signaling pathway is one of the most frequently dysregulated pathways in human cancer (31). In order to evaluate the association between H19 and the RAS-MAPK signaling pathway, a Ras activity assay was performed following transfection with H19 full-length sequence and siRNA against H19 in SW480 and HCT116 cells. The overexpression of H19 was able to upregulate the expression level of active Ras (Fig. 6A), whereas the knockdown of H19 was able to downregulate the expression level of active Ras (Fig. 6B). These results indicate that H19 may affect the expression level of active Ras.

$H 19$ affects the level of $p$-Raf, $p$-ERK and $p$-MEK. The underlying molecular mechanism of H19 in promoting cell migration and invasion, and the association between H19 and the RAS-MAPK signaling pathway were evaluated. The phosphorylation of Raf, ERK and MEK is an important element of the RAS-MAPK signaling pathway. The level of p-Raf, p-ERK and p-MEK was analyzed using western blotting. The overexpression of H19 was able to 

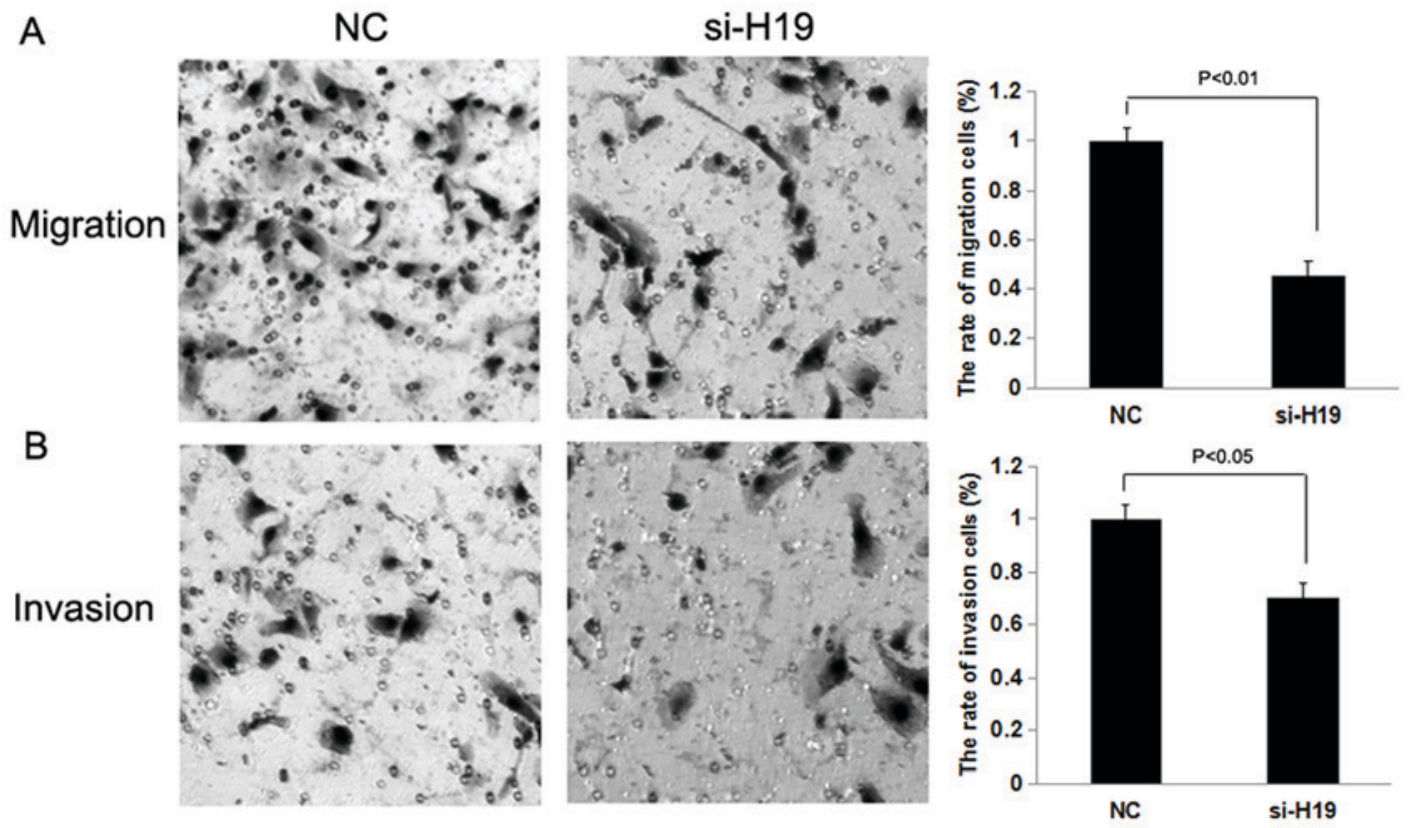

Figure 5. H19 knockdown inhibits the migration and invasion of SW480 cells. (A) H19 knockdown inhibits the migration of SW480 cells (B) H19 knockdown inhibits the invasion of SW480 cells (magnification, x200).

A

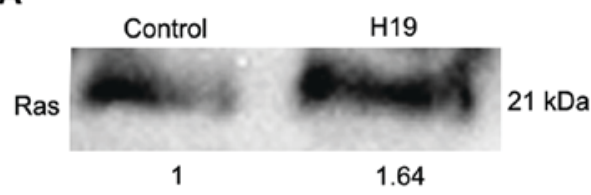

B

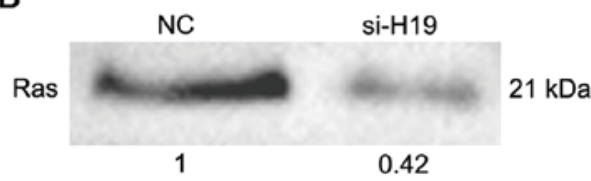

Figure 6. H19 upregulates the expression level of active Ras. (A) Overexpression of H19 upregulates the expression level of active Ras. (B) H19 knockdown downregulates the expression level of active Ras. NC, negative control.

increase the phosphorylation level of Raf, ERK and MEK (Fig. 7A), whereas H19 knockdown decreased the level of p-Raf, p-ERK and p-MEK (Fig. 7B). The results suggest that H19 may be able to regulate the level of p-Raf, p-ERK and p-MEK.

Effect of H19 on cell migration and invasion may be reversed by treatment with a MAPK inhibitor. To determine whether H19 promotes cell migration and invasion through the RAS-MAPK signaling pathway, H19-overexpressed SW480 and HCT116 cells were treated with a MAPK inhibitor, and subsequently Transwell migration and invasion assays were performed. The rates of cell migration and invasion were decreased following treatment with the MAPK inhibitor $(\mathrm{P}<0.01$; Figs. 8 and 9$)$. The results indicated that the inhibition of MAPK was able to decrease the effect of $\mathrm{H} 19$ on cell migration and invasion on SW480 and HCT116 cells.

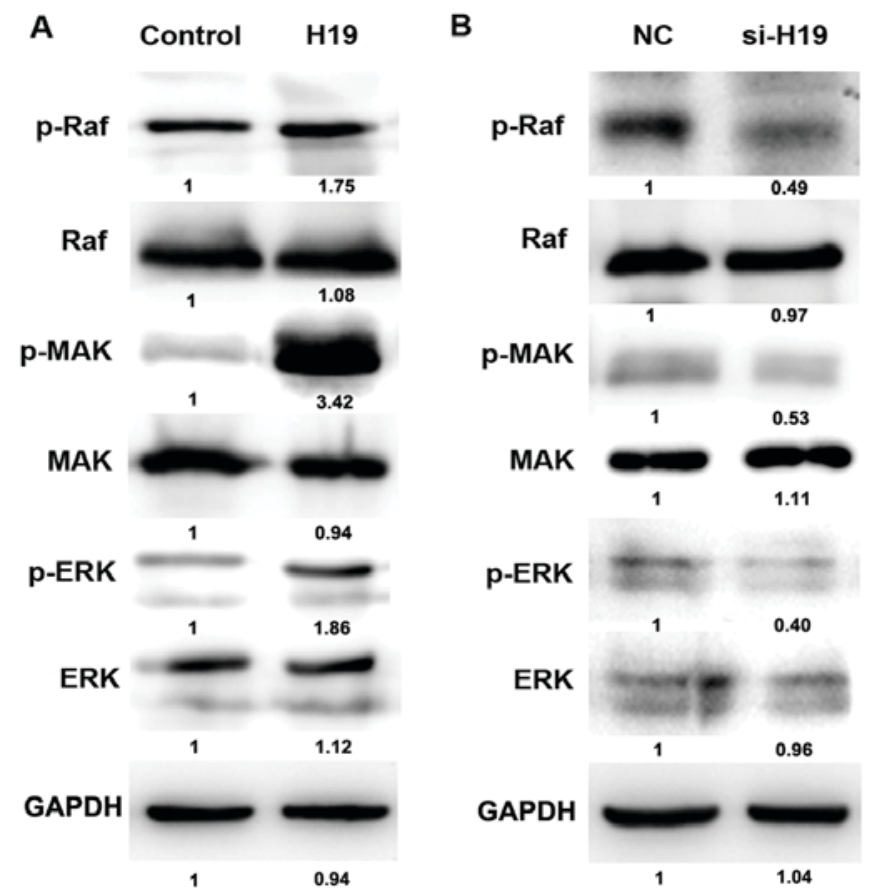

Figure 7. H19 increases the level of p-Raf, p-ERK and p-MEK (A) Overexpression of $\mathrm{H} 19$ increases the level of p-Raf, p-ERK and p-MEK. (B) H19 knockdown decreases the phosphorylation level of p-Raf, p-ERK and p-MEK. MEK, mitogen-activated protein kinase kinase; ERK, extracellular signal-related kinase; p-, phosphorylated.

\section{Discussion}

lncRNAs serve important functions in a number of biological processes, including cell cycle, proliferation, apoptosis, differentiation and invasion (34-36). Numerous studies have demonstrated that lncRNAs are important molecules in human malignancies (19-21,37-39). However, the functions of IncRNAs 

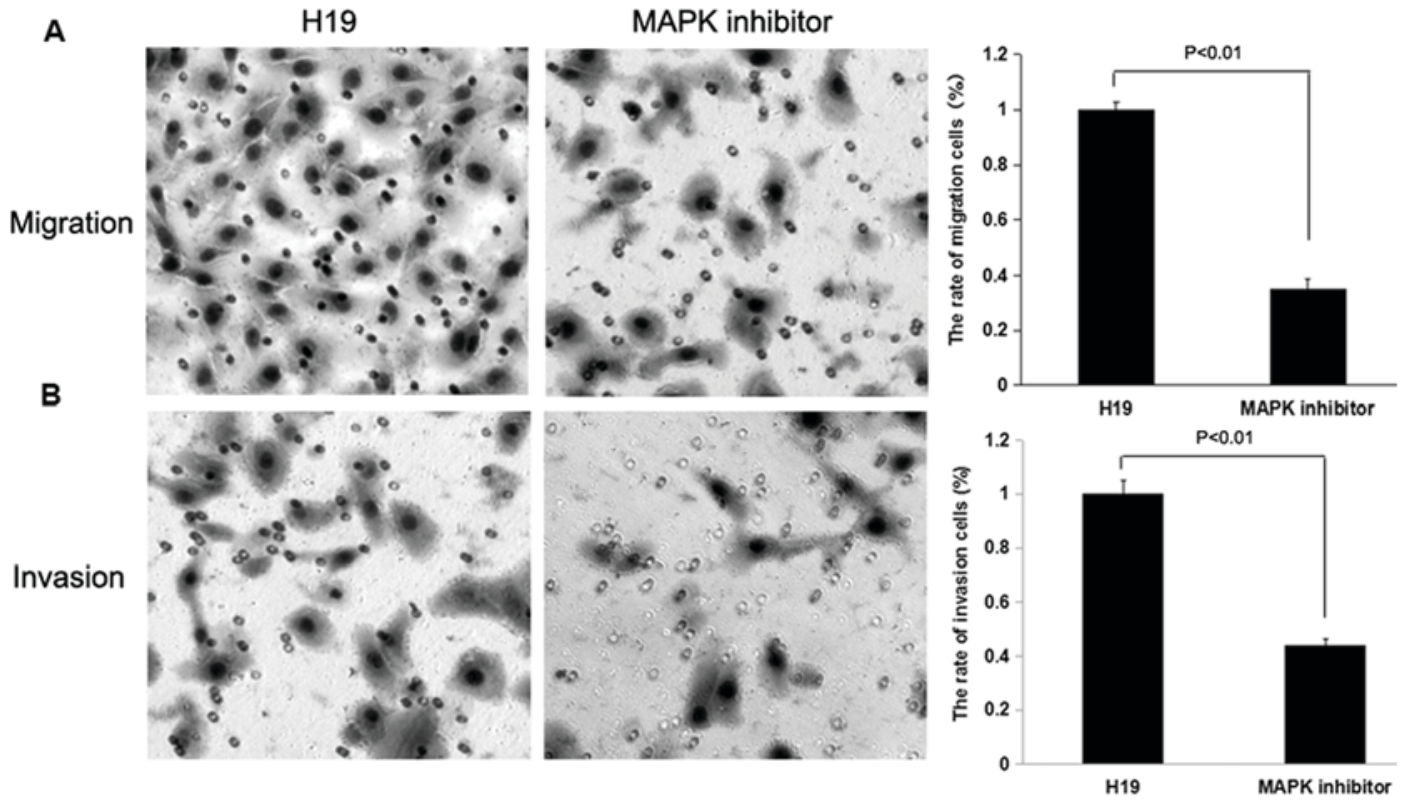

Figure 8. Inhibition of MAPK decreased the effect of H19 on the migration and invasion of HCT116 cells. (A) Treatment with a MAPK inhibitor decreased the effect of H19 on the migration of HCT116 cells. (B) Treatment with a MAPK inhibitor decreased the effect of H19 on the invasion of HCT116 cells (magnification, x200).
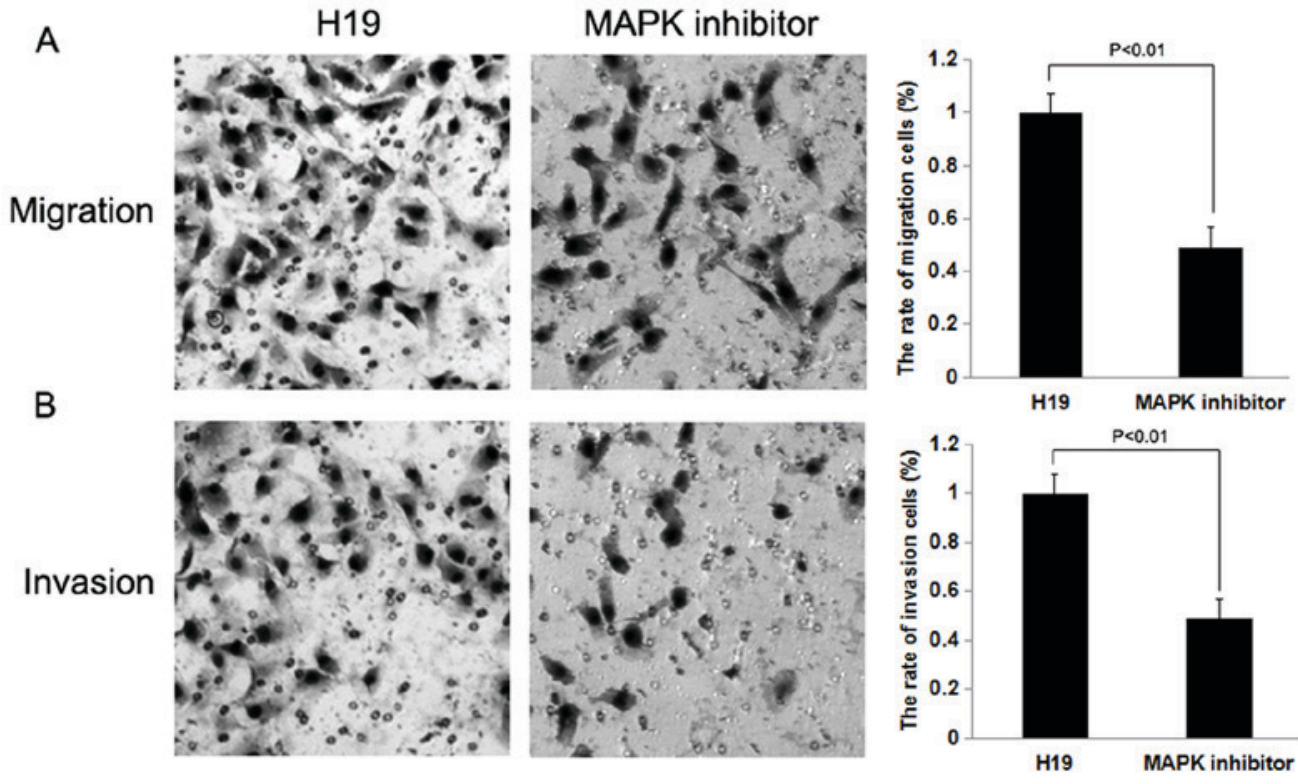

Figure 9. Inhibition of MAPK decreased the effect of H19 on the migration and invasion of SW480 cells. (A) Inhibition of MAP decreased the effect of H19 on the migration of SW480 cells. (B) Inhibition of MAPK decreased the effect of H19 on the invasion of SW480 cells (magnification, x200).

and the underlying molecular mechanism of the oncogenicity of lncRNAs are not well understood. Previous studies have suggested that IncRNA H19 is overexpressed in a variety of types of cancer and that $\mathrm{H} 19$ promotes cancer progression $(22,40,41)$. For example, it was previously demonstrated that $\mathrm{H} 19$ promoted the proliferation of colorectal cancer cells via a competing endogenous RNA mechanism (42). By binding to miR-200a, H19 increased the level of CTNNB1, which is a target of miR-200a, and therefore facilitated the proliferation of CRC cells (42). Similarly, it has been identified that H19 may promote epithelial to mesenchymal transition by acting as a 'miRNA sponge' in colorectal cancer (43). Previous research has demonstrated that $\mathrm{H} 19$ is an oncogene and promotes the proliferation and metastasis of CRC cells (44). With regard to the underlying molecular mechanisms of $\mathrm{H} 19$ in promoting the progression of CRC, a number of studies have focused on the functions of $\mathrm{H} 19$ as a competing endogenous RNA or 'miRNA sponge' $(43,45)$. In the present study, it has been demonstrated that H19 may promote the migration and invasion of colorectal cancer cells via a novel mechanism.

The Ras/Raf/MEK/ERK cascade couples signals from cell-surface receptors to transcription factors, and they may be able to regulate gene expression (31). This signaling pathway may also be activated in certain tumors via the overexpression 
of wild-type or mutated receptor, including epidermal growth factor receptor, chromosomal translocations of breakpoint cluster region-c-abl oncogene 1 (BCR-ABL) and cytokine receptor mutations e.g., Fms related tyrosine kinase 3 (31).

Ras, a small guanosine triphosphate-binding protein, is one of the most common upstream molecules of certain signaling pathways, including Raf/MEK/ERK (46). In total, four types of Ras have been identified: Ha-Ras, N-Ras, Ki-Ras 4A and $\mathrm{Ki}-\mathrm{Ras}$ 4B. Ki-Ras 4A and Ki-Ras 4B are generated from the same gene by alternative splicing. Ki-Ras is a strong inducer of the Raf/MEK/ERK signaling cascade compared with Ha-Ras and is more frequently mutated in human cancer (47). The overexpression of the Ras/Raf/MEK/ERK signaling pathway has been implicated in advanced prostate cancer and has been associated with poor patient prognosis (48). The molecules in the Ras/Raf/MEK/ERK signaling pathway, which act as growth factors may be induced by autocrine and paracrine signaling (49). However, a number of studies assessed the function of the RAS-MAPK signaling pathway in human colorectal cancer, particularly the combined functions of H19 and the RAS-MAPK signaling pathway. In the present study, in order to investigate whether H19 promotes invasion and migration via activation of MAPK signaling, MAPK was inhibited and the effect of H19 on migration and invasion of cancer cells was assessed. The results revealed that the inhibition of MAPK was able to suppress the pro-metastatic function of H19, which supports the hypothesis that $\mathrm{H} 19$ promotes the migration and invasion of cancer cells via activation of MAPK signaling. However, the present study has only identified the association between $\mathrm{H} 19$ and RAS-MAPK signaling pathway in CRC using in vitro techniques. Therefore, in vivo experiments should be carried out to corroborate the in vitro data.

In conclusion, H19 may promote the migration and invasion of CRC cells, by activating Ras protein and upregulating the levels of p-Raf, p-MEK and p-ERK. H19 may facilitate the migration and invasion of CRC cells via the RAS-MAPK signaling pathway.

\section{Acknowledgements}

Not applicable.

\section{Funding}

The present study was supported by the Fundamental Research Funds for the Provincial Universities (grant no. 2017-KYYWF-0289), the National Natural Science Foundation of China (grant no. 81201688) and The Key Program of Pecking University International Hospital Scientific Research Foundation (grant no. YN2016ZD04).

\section{Availability of data and materials}

The datasets used and/or analyzed during the current study are available from the corresponding author on reasonable request.

\section{Authors' contributions}

NN conceived and designed the experiments. WY, RER and $\mathrm{CZ}$ performed the experiments and analyzed the data. WY and
$\mathrm{CZ}$ wrote the manuscript. All authors read and approved the final manuscript.

\section{Ethics approval and consent to participate}

Not applicable.

\section{Patient consent for publication}

Not applicable.

\section{Competing interests}

The authors declare that they have no competing interests.

\section{References}

1. Karsa LV, Lignini TA, Patnick J, Lambert R and Sauvaget C: The dimensions of the CRC problem. Best Pract Res Clin Gastroenterol 24: 381-396, 2010.

2. Chen W, Zheng R, Zeng H, Zhang S and He J: Annual report on status of cancer in China, 2011. Chin J Cancer Res 27: 2-12, 2015.

3. Zhou M, Zhao H, Wang Z, Cheng L, Yang L, Shi H, Yang H and Sun J: Identification and validation of potential prognostic IncRNA biomarkers for predicting survival in patients with multiple myeloma. J Exp Clin Cancer Res 34: 102, 2015.

4. Fatica A and Bozzoni I: Long non-coding RNAs: New players in cell differentiation and development. Nat Rev Genet 15: 7-21, 2014.

5. St Laurent G, Wahlestedt C and Kapranov P: The Landscape of long noncoding RNA classification. Trends Genet 31: 239-251, 2015.

6. Shang C, Guo Y, Zhang $\mathrm{H}$ and Xue YX: Long noncoding RNA HOTAIR is a prognostic biomarker and inhibits chemosensitivity to doxorubicin in bladder transitional cell carcinoma. Cancer Chemother Pharmacol 77: 507-513, 2016.

7. Sun J, Shi H, Wang Z, Zhang C, Liu L, Wang L, He W, Hao D, Liu S and Zhou M: Inferring novel lncRNA-disease associations based on a random walk model of a lncRNA functional similarity network. Mol Biosyst 10: 2074-2081, 2014.

8. Zhou M, Wang X, Li J, Hao D, Wang Z, Shi H, Han L, Zhou H and Sun J: Prioritizing candidate disease-related long non-coding RNAs by walking on the heterogeneous lncRNA and disease network. Mol Biosyst 11: 760-769, 2015.

9. Zhou M, Xu W, Yue X, Zhao H, Wang Z, Shi H, Cheng L and Sun J: Relapse-related long non-coding RNA signature to improve prognosis prediction of lung adenocarcinoma. Oncotarget 7: 29720-29738, 2016

10. Sun J, Chen X, Wang Z, Guo M, Shi H, Wang X, Cheng L and Zhou M: A potential prognostic long non-coding RNA signature to predict metastasis-free survival of breast cancer patients. Sci Rep 5: $16553,2015$.

11. Zhou M, Zhao H, Xu W, Bao S, Cheng L and Sun J: Discovery and validation of immune-associated long non-coding RNA biomarkers associated with clinically molecular subtype and prognosis in diffuse large B cell lymphoma. Mol Cancer 16: 16, 2017.

12. Zhou M, Zhang Z, Zhao H, Bao S, Cheng L and Sun J: An immune-related six-lncRNA signature to improve prognosis prediction of glioblastoma multiforme. Mol Neurobiol 55: 3684-3697, 2017

13. Morris KV: Long antisense non-coding RNAs function to direct epigenetic complexes that regulate transcription in human cells. Epigenetics 4: 296-301, 2009.

14. Ricciuti B, Mencaroni C, Paglialunga L, Paciullo F, Crinò L, Chiari R and Metro G: Long noncoding RNAs: New insights into non-small cell lung cancer biology, diagnosis and therapy. Med Oncol 33: 18, 2016.

15. Guo Q, Cheng Y, Liang T, He Y, Ren C, Sun L and Zhang G: Comprehensive analysis of IncRNA-mRNA co-expression patterns identifies immune-associated lncRNA biomarkers in ovarian cancer malignant progression. Sci Rep 5: 17683, 2015.

16. Qiu M, Feng D, Zhang H, Xia W, Xu Y, Wang J, Dong G, Zhang Y, Yin R and Xu L: Comprehensive analysis of lncRNA expression profiles and identification of functional lncRNAs in lung adenocarcinoma. Oncotarget 7: 16012-16022, 2016. 
17. Sun J, Cheng L, Shi H, Zhang Z, Zhao H, Wang Z and Zhou M: A potential panel of six-long non-coding RNA signature to improve survival prediction of diffuse large-B-cell lymphoma. Sci Rep 6: 27842, 2016.

18. Yang L, Yi K, Wang H, Zhao Y and Xi M: Comprehensive analysis of lncRNAs microarray profile and mRNA-lncRNA co-expression in oncogenic HPV-positive cervical cancer cell lines. Oncotarget 7: 49917-49929, 2016.

19. Zhou M, Guo M, He D, Wang X, Cui Y, Yang H, Hao D and Sun J: A potential signature of eight long non-coding RNAs predicts survival in patients with non-small cell lung cancer. J Transl Med 13: 231, 2015.

20. Zhou M, Sun Y, Sun Y, Xu W, Zhang Z, Zhao H, Zhong Z and Sun J: Comprehensive analysis of lncRNA expression profiles reveals a novel lncRNA signature to discriminate nonequivalent outcomes in patients with ovarian cancer. Oncotarget 7: 32433-32448, 2016.

21. Zhou M, Wang X, Shi H, Cheng L, Wang Z, Zhao H, Yang L and Sun J: Characterization of long non-coding RNA-associated ceRNA network to reveal potential prognostic lncRNA biomarkers in human ovarian cancer. Oncotarget 7: 12598-12611, 2016.

22. Keniry A, Oxley D, Monnier P, Kyba M, Dandolo L, Smits G and Reik W: The H19 lincRNA is a developmental reservoir of miR-675 that suppresses growth and Igf1r. Nat Cell Biol 14: 659-665, 2012.

23. Cui H, Onyango P, Brandenburg S, Wu Y, Hsieh CL and Feinberg AP: Loss of imprinting in colorectal cancer linked to hypomethylation of H19 and IGF2. Cancer Res 62: 6442-6446, 2002.

24. Tsang WP, Ng EK, Ng SS, Jin H, Yu J, Sung JJ and Kwok TT: Oncofetal H19-derived miR-675 regulates tumor suppressor RB in human colorectal cancer. Carcinogenesis 31: 350-358, 2010.

25. Matouk IJ, DeGroot N, Mezan S, Ayesh S, Abu-lail R Hochberg A and Galun E: The H19 non-coding RNA is essential for human tumor growth. PLoS One 2: e845, 2007.

26. Ariel I, Miao HQ, Ji XR, Schneider T, Roll D, de Groot N, Hochberg A and Ayesh S: Imprinted H19 oncofetal RNA is a candidate tumour marker for hepatocellular carcinoma. Mol Pathol 51: 21-25, 1998.

27. Hibi K, Nakamura H, Hirai A, Fujikake Y, Kasai Y, Akiyama S, Ito $\mathrm{K}$ and Takagi $\mathrm{H}$ : Loss of $\mathrm{H} 19$ imprinting in esophageal cancer. Cancer Res 56: 480-482, 1996.

28. Byun HM, Wong HL, Birnstein EA, Wolff EM, Liang G and Yang AS: Examination of IGF2 and H19 loss of imprinting in bladder cancer. Cancer Res 67: 10753-10758, 2007.

29. Berteaux N, Lottin S, Monté D, Pinte S, Quatannens B, Coll J, Hondermarck H, Curgy JJ, Dugimont T and Adriaenssens E: H19 mRNA-like noncoding RNA promotes breast cancer cell proliferation through positive control by E2F1. J Biol Chem 280: 29625-29636, 2005.

30. Lottin S, Adriaenssens E, Dupressoir T, Berteaux N, Montpellier C, Coll J, Dugimont T and Curgy JJ: Overexpression of an ectopic $\mathrm{H} 19$ gene enhances the tumorigenic properties of breast cancer cells. Carcinogenesis 23: 1885-1895, 2002.

31. McCubrey JA, Steelman LS, Chappell WH, Abrams SL, Wong EW, Chang F, Lehmann B, Terrian DM, Milella M, Tafuri A, et al: Roles of the Raf/MEK/ERK pathway in cell growth, malignant transformation and drug resistance. Biochim Biophys Acta 1773: 1263-1284, 2007.

32. Li X, Zhang J, Gao L, McClellan S, Finan MA, Butler TW, Owen LB, Piazza GA and Xi Y: MiR-181 mediates cell differentiation by interrupting the Lin28 and let-7 feedback circuit. Cell Death Differ 19: 378-386, 2012.

33. Schmittgen TD and Livak KJ: Analyzing real-time PCR data by the comparative C(T) method. Nat Protoc 3: 1101-1108, 2008.
34. Khaitan D, Dinger ME, Mazar J, Crawford J, Smith MA, Mattick JS and Perera RJ: The melanoma-upregulated long noncoding RNA SPRY4-IT1 modulates apoptosis and invasion. Cancer Res 71: 3852-3862, 2011.

35. Calin GA, Liu CG, Ferracin M, Hyslop T, Spizzo R, Sevignani C, Fabbri M, Cimmino A, Lee EJ, Wojcik SE, et al: Ultraconserved regions encoding ncRNAs are altered in human leukemias and carcinomas. Cancer Cell 12: 215-229, 2007.

36. Braconi C, Valeri N, Kogure T, Gasparini P, Huang N, Nuovo GJ, Terracciano L, Croce CM and Patel T: Expression and functional role of a transcribed noncoding RNA with an ultraconserved element in hepatocellular carcinoma. Proc Natl Acad Sci USA 108: 786-791, 2011.

37. Mercer TR, Dinger ME and Mattick JS: Long non-coding RNAs: Insights into functions. Nat Rev Genet 10: 155-159, 2009.

38. Ji P, Diederichs S, Wang W, Böing S, Metzger R, Schneider PM, Tidow N, Brandt B, Buerger H, Bulk E, et al: MALAT-1, a novel noncoding RNA, and thymosin beta4 predict metastasis and survival in early-stage non-small cell lung cancer. Oncogene 22: 8031-8041, 2003

39. Ponting CP, Oliver PL and Reik W: Evolution and functions of long noncoding RNAs. Cell 136: 629-641, 2009.

40. Matouk IJ, Halle D, Raveh E, Gilon M, Sorin V and Hochberg A: The role of the oncofetal H19 lncRNA in tumor metastasis: Orchestrating the EMT-MET decision. Oncotarget 7: 3748-3765, 2016.

41. Xia T, Liao Q, Jiang X, Shao Y, Xiao B, Xi Y and Guo J: Long noncoding RNA associated-competing endogenous RNAs in gastric cancer. Sci Rep 4: 6088, 2014.

42. Yang W, Ning N and Jin X: The lncRNA H19 promotes cell proliferation by competitively binding to miR-200a and derepressing $\beta$-catenin expression in colorectal cancer. Biomed Res Int 2017: 2767484, 2017

43. Liang WC, Fu WM, Wong CW, Wang Y, Wang WM, Hu GX, Zhang L, Xiao LJ, Wan DC, Zhang JF and Waye MM: The lncRNA H19 promotes epithelial to mesenchymal transition by functioning as miRNA sponges in colorectal cancer. Oncotarget 6: 22513-22525, 2015.

44. Liang W, Zou Y, Qin F, Chen J, Xu J, Huang S, Chen J and Dai S: sTLR4/MD-2 complex inhibits colorectal cancer migration and invasiveness in vitro and in vivo by lncRNA H19 downregulation. Acta Biochim Biophys Sin (Shanghai) 49: 1035-1041, 2017.

45. Ohtsuka M,Ling H, Ivan C, Pichler M, Matsushita D, Goblirsch M, Stiegelbauer V, Shigeyasu K, Zhang X, Chen M, et al: H19 Noncoding RNA, an independent prognostic factor, regulates essential Rb-E2F and CDK8- $\beta$-catenin signaling in colorectal cancer. EBioMedicine 13: 113-124, 2016.

46. Peyssonnaux C, Provot S, Felder-Schmittbuhl MP, Calothy G and Eychène A: Induction of postmitotic neuroretina cell proliferation by distinct Ras downstream signaling pathways. Mol Cell Biol 20: 7068-7079, 2000.

47. Yan J, Roy S, Apolloni A, Lane A and Hancock JF: Ras isoforms vary in their ability to activate Raf-1 and phosphoinositide 3-kinase. J Biol Chem 273: 24052-24056, 1998.

48. Gioeli D, Mandell JW, Petroni GR, Frierson HF Jr and Weber MJ: Activation of mitogen-activated protein kinase associated with prostate cancer progression. Cancer Res 59: 279-284, 1999.

49. Abreu-Martin MT, Chari A, Palladino AA, Craft NA and Sawyers CL: Mitogen-activated protein kinase kinase kinase 1 activates androgen receptor-dependent transcription and apoptosis in prostate cancer. Mol Cell Biol 19: 5143-5154, 1999. 